\title{
OO. TASK39
}

\section{Thermal limitation of glazed collector for DHW INFO Sheet B6}

\begin{tabular}{l|l} 
Description: & $\begin{array}{l}\text { Dry stagnation Overheating protection based on automatic venting of collector } \\
\text { casing. }\end{array}$ \\
\hline Date: & May 2015 \\
\hline Authors: & Michael Plaschkes, Magen -ecoenergy Kibutz Magen /Israel \\
\hline
\end{tabular}

\section{Introduction}

A plastic collector using a Polyolefin absorber, a Nylon glass reinforced casing and a double wall Polycarbonate glazing were designed. In order to limit the dry stagnation temperature to an acceptable level $\left(120^{\circ} \mathrm{C}\right)$ it was necessary to invent a venting system which would function without external intervention.

The polyolefin absorber will expand due to its inherent thermal expansion coefficient. This change in total length of approximately $30 \mathrm{~mm}$ is exploited to open particularly designed venting orifices situated on the lateral sides of the collector frame. This automatically controlled device produces a thermo-gravitational air flow throughout the collector casing and reduces the stagnation temperature to an acceptable level for the specially formulated heat resistant polyolefin used for the absorber. NB: this system is patented by Magen-Eco -energy.

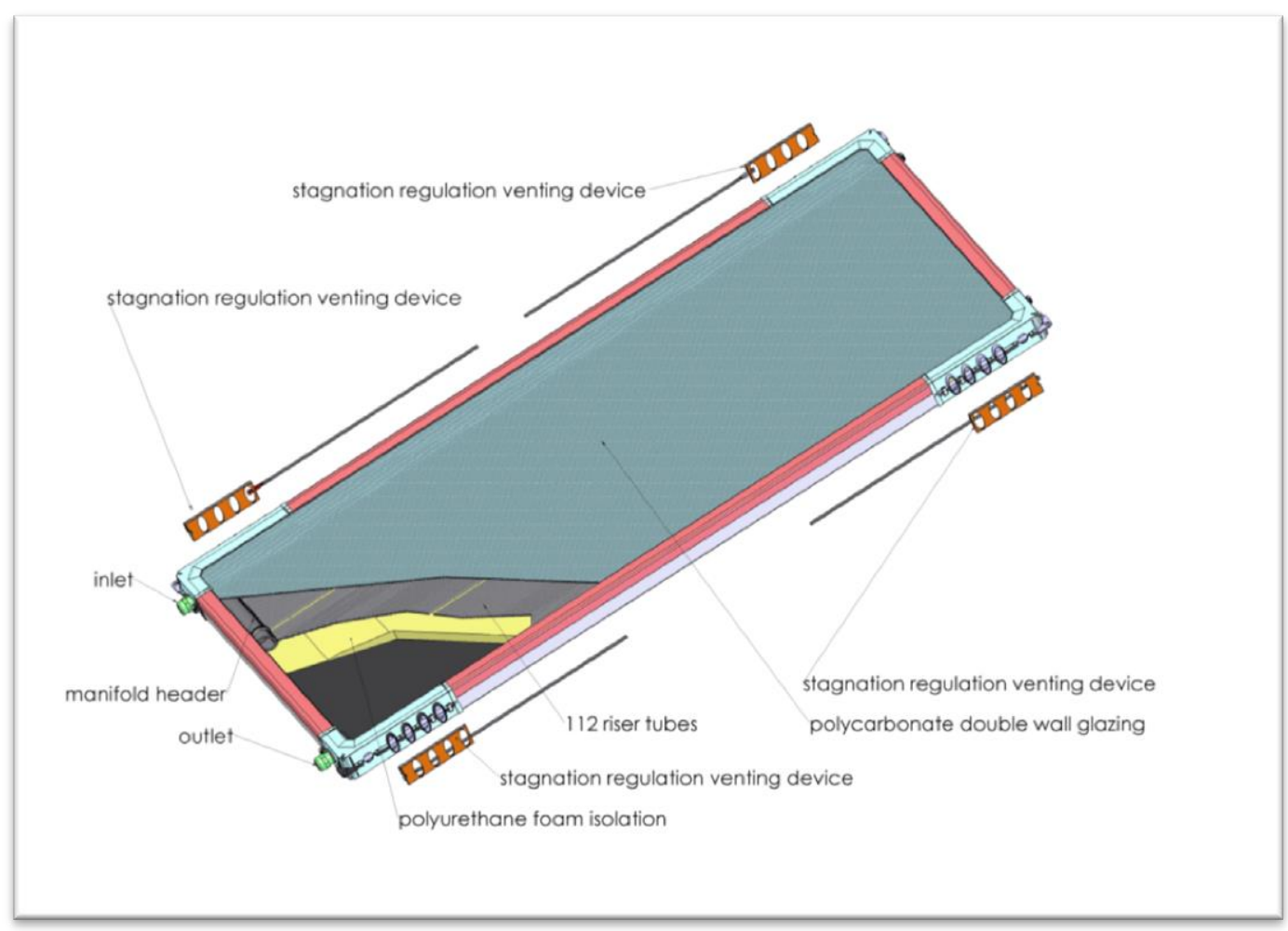




\section{Thermal limitation of glazed collector for DHW INFO Sheet B6}

\section{Measurements and results:}

1) The effectiveness of the system is influenced by the installation angle of the collector. The upper vents should be situated higher above the lower vents in order to generate a thermo-gravitational air flow. Thus an installation angle of $45^{\circ}$ will produce better results compared to a $30^{\circ}$ angle.

2) Temperature tests measured during the months June, July, August 2012 in the Negev climate at Kibbutz Magen (Israel) showed that this collector system installed at an tilt angle of $39^{\circ}$ limited the absorber dry stagnation temperature at its upper position ( $2 / 3$ height) to a maximum of $128{ }^{\circ} \mathrm{C}$ when compared to an unprotected collector. The temperature reduction is approximately $15^{\circ} \mathrm{C}$.

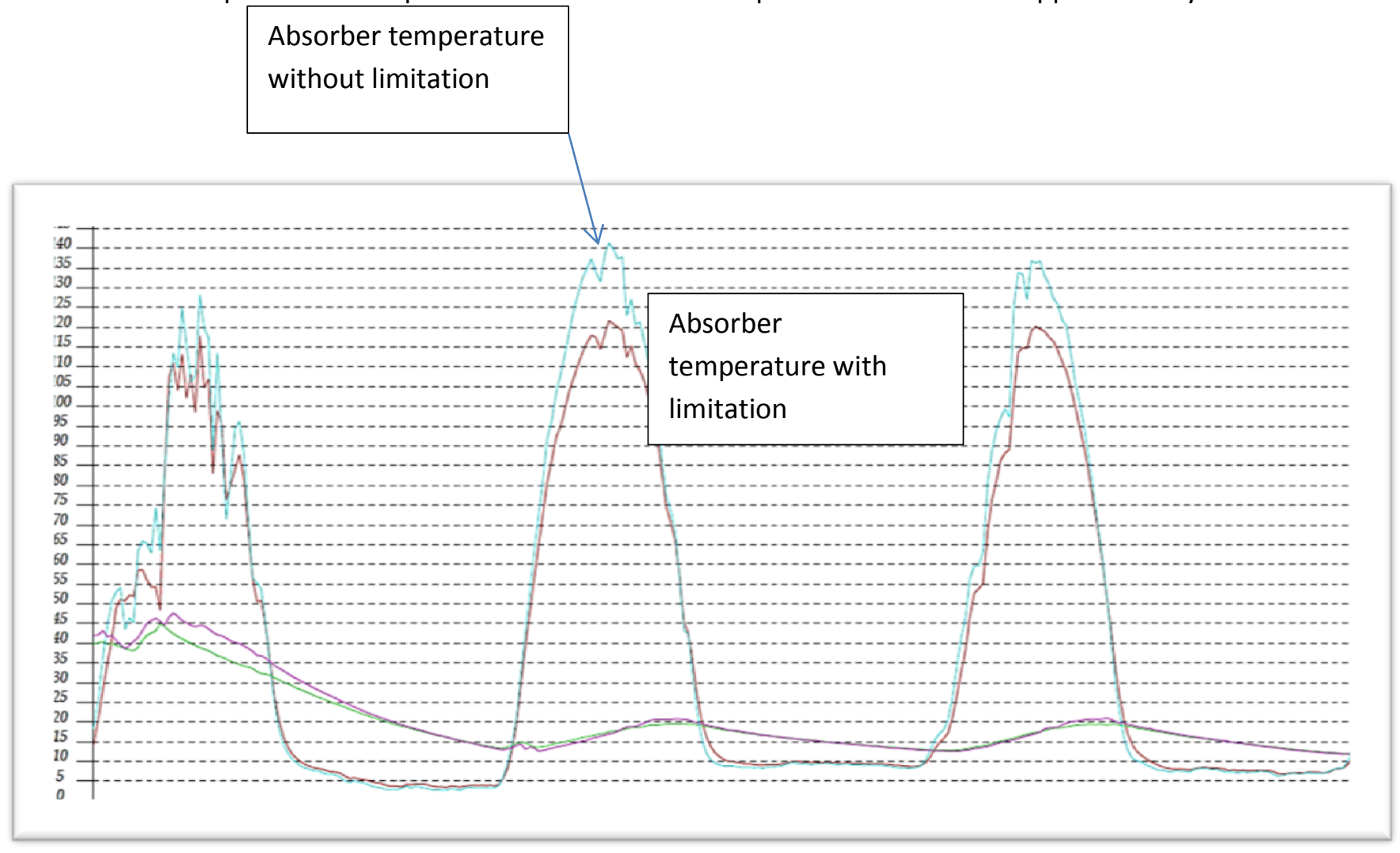

TYPICAL MEASUREMENTS: 3 days in JULY 2012:

Max radiation $1015 \mathrm{~W} / \mathrm{m}^{2}$ and maximum ambient air temperature $35^{\circ} \mathrm{C}$ 